\title{
Reports of coerced sterilization of Indigenous women in Canada mirrors shameful past
}

\author{
— Cite as: CMAJ 2017 August 21;189:E1080-1. doi: 10.1503/cmaj.1095471
}

Posted on cmajnews.com on Aug. 2, 2017.

$\mathrm{T}$ he practice of coerced sterilization of Indigenous women, an act condemned by human rights' organizations around the world, was supposed to have ended in Canada in the early 1970s. Yet today, four decades later, it still appears in news articles rather than just history books.

According to the report "Tubal Ligation in the Saskatoon Health Region: The Lived Experience of Aboriginal Women," released July 27 , several Indigenous women have reported being coerced into having tubal ligations in Saskatoon hospitals. The women say they were pressured by health care workers to undergo the procedure while in labor. Some did not fully understand the consequences, believing the procedure to be reversible.

"I think a main message would be that is there a wide gap between the health care provider's knowledge base and life experience versus an Aboriginal woman's life experience," said Yvonne Boyer, coauthor of the report and a Canada Research Chair in Aboriginal Health and Wellness at Brandon University in Winnipeg. "There is a clear disconnect between the two worldviews. It is impossible for the health care provider to comprehend and understand the Aboriginal women's life experience without a willingness to undergo serious culturally appropriate education."

The women interviewed for the report said they were made to feel "invisible, profiled and powerless." One of the women, Melika Popp, who is considering a lawsuit against Saskatoon Health Region, said no

\section{Eliminating forced, coercive and} otherwise involuntary sterilization An interagency statement

OHCHR

UN Women

UNAIDS

UNDP

UNFPA

UNICEF

WHO

(6)

Meanwhile, the two authors of the report - Boyer and Dr. Judith Bartlett, an Aboriginal physician and former associate professor of community health science at the University of Manitoba - have called for a national review to determine if Indigenous women in other parts of Canada have "experienced similar trauma." Since the report came out, Boyer has been contacted by several more women - from Alberta, Manitoba and Southern Saskatchewan - with similar stories.

"We don't have to look very far to see that this issue is insidious, widespread and devastating to the women and families who have experienced a coerced tubal ligation," said Boyer. "And that, indeed, is a very good reason for a national review."

Reaction to the report has been swift

one should be asked to make "such a drastic, life-altering decision" in the middle of childbirth. Others have said they feel robbed of part of their womanhood, and that romantic relationships have ended after partners learned they could no longer bear children.

Saskatoon Health Region has acknowledged that racism exists within its health care system. Representatives of the health region have issued formal apologies. "No woman should be treated the way you were treated," stated Jackie Mann, vicepresident of integrated health services for the health region. The health region's news release praised the courage of the Indigenous women who told their stories, stating "You have been heard and will be listened to." and critical. In an editorial, the Saskatoon StarPhoenix said the apologies "should have come more quickly." The newspaper had reported on the allegations in the middle of 2015. The health region started an independent review, but "quietly cancelled the investigation" in June of 2016. The current report, and the six-month investigation that preceded it, only came about after additional media pressure, according to the editorial.

The experiences of the Saskatoon women were "horrendous and disturbing," said Heather Bear, a vice-chief of the Federation of Sovereign Indigenous Nations. According to Arthur Schafer, director of the Centre for Professional and Applied Ethics at the University of Manitoba, pressuring 
Aboriginal women into tubal ligation is egregious, blatant and "clearly racist". It is also a "teaching moment" for every health care facility in Canada, he said, because it's unlikely it was confined to one or two health authorities or a few First Nations women.

"The apology from the health authority was full-hearted. There was no shillyshallying; there were no weasel-words," said Schafer, who also praised the health region for taking steps to revise its sterilization policy. "But one fears that racism against First Nations people, both explicit and systemic, is so pervasive in Canadian society that it cannot truly be eradicated from our hospitals until there has been deep structural change in the wider society."

In the 1970s, reportedly to reduce the size of Indigenous communities, there were about 1200 cases of coerced sterilization among Aboriginal women in Canada. Almost half of the procedures were performed at "Indian" hospitals operated by the federal government. According to one Canadian researcher who wrote a book on the subject, it was nothing less than an act of genocide.

"How is it possible, after Canada's shameful history of sterilizing Aboriginal women on the spurious grounds of 'men- tal unfitness,' that similar kinds of abuse could still be occurring in a Canadian hospital?" said Schafer. "Is the lack of respect and compassion for Indigenous women, which the report describes, occurring at other Canadian hospitals? If so, how common is such abuse?"

Other countries have also initiated sterilization efforts to reduce the birth rates of Indigenous populations. In the United States, thousands of Native American women were coerced into tubal ligation during the 1960s and 1970s. Again, consent was not considered necessary. Some of the women had entered treatment facilities for other procedures, such as a tonsillectomy or appendectomy, only to return home with fallopian tubes that were tied or cut.

More recently, in 1996, Peru introduced the Reproductive Health and Family Planning Programme. Indigenous women in poor, rural communities were targeted by the country's health ministry for sterilization without consent. More than 260000 women were reported to have undergone tubal ligation between 1996 and 2000, and patient consent was given in as few as $10 \%$ of cases. The intent of the program was to reduce birth rates in low-income homes in an effort to reduce poverty levels.
Any form of coercive or involuntary sterilization, however, is a "violation of fundamental human rights, including the right to health, the right to information, the right to privacy, the right to decide the number and spacing of children, the right to found a family and the right to be free from discrimination," according to a 2014 report by the World Health Organization, UN Women and other agencies. Involuntary sterilization is not only unethical, the report states, it is an act of violence against women.

The Saskatoon report also mentions the historical context of sterilization policies in Canada, noting that they have had "great detrimental effects on Indigenous women." In response to the recent experiences of the women in Saskatoon, the report concludes with several calls to action, including mandatory cultural training for health care workers, cultural competency education in nursing and medical schools, a revision of the tubal ligation consent policies, and the implementation of a framework for Aboriginal rights that would ensure reproductive and traditional health practices are considered constitutionally protected rights.

Roger Collier, CMAJ 